\title{
sobre la estructura del clínker de cemento portland
}

\author{
trabajo presentado en la Ill reunión internacional sobre reactividad \\ de sólidos, con este mismo título
}

J. CALLEJA CARRETE

doctor en eiencias quimicas

SI NOP S I S

Estudiada por el autor, on dos trabajos, la distribuolón heterozénea de la cal libre, asi como la de otros componentes de oarácter ácido y fundente, en los gránulos de elinker de cemento portland, al considerar en ellos zonss externas, intermedias e internas, se confirman $y$ amplian en la presente comunicación los resultados anterlormente obtenidos.

Para ello se ha utilizado un método de trabajo alistinto, que permite, comprobar dos de las conclusiones emitidar previamente como eventuales.

Los resultados hallados permiten apreciar nn desizual reparto de componentes quimicos entre las distintas zonas de los granulos de clínker, en el sentido de que on las capas externas de éstos obundan más los fundentes y, por tanto los aluminatos $y$ aluminoferritos ćlclicos, asf como la magnesia, mientras en el interior son más abunantes la ailice, ei silicato bicâlcice y la cal libre.

Los módujos hidráulios, silíito $y$ de fundentes, asi como los porcentajes de fase lígulda dados por las fórmulas dé Lea y Parker, varian, de acuerdo con lo anterior, en la forma previsible.

\section{1.-INTRODUCCION.}

En trabajos anteriores, cuyos resultados y conclusiones dieron lugar a la realización del presente, se pusieron de maniflesto dos hechos muy notorios: uno, el de la distribución heterogénea de la cal libre en los gránulos. de clínker, cuando en ellos se consideran tres zonas diferentes: una cortical o periférica, otra intermedia y otra interna o nuclear. De tal manera, que la cal no combinada es más abundante en las zonas nucleares, donde alcanza valores máximos, que en las zonas periféricas, en las que es poco abundante 0 inexistente (1).

Una posible explicación inmediata del hecho podria ser la de la meteorización de Ios gránulos. En efecto, por exposición a la intemperie, o por rociado del clínker con agua a la salida del horno, como suele practicarse a veces en algunas fábricas, todo o gran parte del CaO libre de la zona cortical podría transformarse en $\mathrm{Ca}(\mathrm{OH})_{2}$ primero $\mathrm{y}$ en $\mathrm{CaCO}_{2}$ después. $\mathrm{El} \mathrm{Ca}(\mathrm{OH})_{2}$, al igual que el $\mathrm{CaO}$, es detectable por el método analítico que se empleaba (2); no asi el $\mathrm{CaCO}_{\mathrm{s}}$, lo cual daría una idea del porqué de la escasez o inexistencia del $\mathrm{CaO}$ libre en las zonas periféricas de los gránulos de clínker, cuando éstos han estado expuestos a una intensa meteorización.

Pero es el caso que este hecho se presenta también en clínkeres que no han sido templados, e incluso que no han tenido tiempo ni ocasión de meteorizarse. Cuanto más que, dada la compacidad y escasa porosidad de la parte externa de los gránulos de clínker, la meteorización sólo afectaría a una capa de un espesor despreciable. En todo caso, en clinkeres con escasísima o nula proporción de cal llbre en la periferia, no se han hallado para ésta valores de la pérdida al fuego que hagan aceptable la Idea de la meteorización.

Dada la heterogeneidad de distribución de la cal llbre en la forma expuesta, como hecho general no atribuíble a causas externas ajenas al propio clinker, era lógico admitir la' heterogeneidad de otros de los restantes compo- 
nentes de aquél, particularmente de los de carácter ácído (sílice) y de los de tipo juntamente ácido y fundente (alúmina y óxido férrico).

A esta heterogeneidad se refieren los resultados del otro trabajo antes mencionado (3), los cuales pueden resumirse así:

En las zonas corticales de los gránulos de clínker existe una mayor cantidad de alúmina y oxido férrico que en las zonas internas. La suma de sesquióxidos es mayor en las primeras que en las segundas. Por el contrario, en éstas abunda más la cal libre y la sílice. En consecuencla, los módulos de ambas zonas difieren en la forma que es previsible, según lo que queda expuesto.

Estos resultados pueden tener también una explicación lógica, admitiendo una acumulaclón de cenizas del combustible, de naturaleza arcillosa; en la parte externa de los gránulos, o bien una falta de homogenefdad en el crudo.

De hecho, se ha comprobado que Ias cenizas del carbón forman a veces, alrededor de los gránulos de clínker, una película o costra, cuya composición es distinta de la composiclón media de aquéllos.

Incluso en el proceso de vía húmeda, utillzando combustibles muy impuros, se han encontrado gránulos de clínker heterogéneos, con zonas bicálcicas de varios milímetros. Estas presentan, en general, una coloración amarillenta, explicable si se admite que las cenizas que se depositan sobre el clínker contienen aún carbono sin quemar, el cual produce una reducción parcial del oxido férrico a ferroso, en el lugar en que se fijan (4).

Con combustibles de menor contenido en cenizas $(25 \%)$, el riesgo de formación de zonas bicálcicas es menor, encontrándose, a veces, en la parte periférica de los gránulos, estrechas fajas de silicato bicálcico, en forma de arco de círculo, a poca distancia del borde. El que, sin embargo, no sea fácll, según Lhopitallier y James (4), observar con el microscopio estas zonas bicálcicas características de un recubrimiento por cenizas en el curso de la formación del gránulo de clínker, puede ser un índice de que la mezcla de aquéllas con eI crudo es intima, resultando un conjunto homogéneo.

Este es tanto más fácli de lograr cuando las cenizas no son ni demasiado arcillosas ni demaslado calcáreas. Las primeras reducen los módulos hidráultco, silícico y de fundentes en zonas del clínker en que, como consecuencia, aparecen formaciones alíticas y beliticas rodeadas de una costra de silicato blcálcico, debido, tal vez, al escaso tiempo de contacto entre la ceniza y el material que se clinkeriza.

Si la ceniza es calcárea y no se mezcla homogéneamente con el crudo, alrededor de los gránulos se forma una costra de material de elevado contenido en cal, la cual se desprende en forma pulverulenta, por fricción. Cuando el contenido en cal de las cenizas no es muy elevado, apenas influyen éstas en la calidad del clínker, puesto que el enriquecimtento en cal sólo afecta a la superficie del materfal. Su costra presenta una proporción de cal muchísimo mayor en su parte interna que en el exterior (5).

La explicación de la formación de las fajas de silleato bicálcico en forma de arco de círculo, cuando son fácilmente observables, es la sigulente: al recubrirse de cenlzas un gránulo de clínker se produce una zona belítica; si se forma después otra capa más externa de crudo normal, ésta da lugar a una zona relativamente más alitica. Ello puede suceder por una parada momentánea del horno. En general, con combustibles de pocas cenizas el clínker es más homogéneo.

De lo expruesto se deduce que el fenómeno de la heterogeneidad no es atribuíble en exclusiva, ni a las cenizas, ni a la falta de homogeneidad del crudo; si bien ambos, y en particular la acumulación de aquéllas en la parte externa de los gránulos, pueden contribuir a acentuarlo.

Lo primero, porque el hecho se da también en gránulos de clínker cocido con fuel-oil, combustible prácticamente exento de cenizas, como se ha podido constatar.

Lo segundo, porque, estadísticamente, la falta de homogeneidad del crudo deberia 
- obrar unas veces en un sentido y otras en otro. $\mathrm{Y}$ porque el fenómeno se presenta tanto en clínkeres obtenidos por vía seca, Ia homogeneldad de cuyos crudos puede a veces considerarse dudosa, como en clínkeres fabricados por vía húmeda, cuyos crudos son homogéneos por excelencia. $Y$, además, porque las citadas heterogeneldades se producen también en clínkeres de cemento natural, en cuya obtención no intervienen procesos de dosiflcación, mezcla y homogeneización.

Se trata, pues, como en el caso de la heterogeneidad de cal libre, de un hecho general inherente al propio clínker.

La heterogeneidad de dístribución de componentes "ácidos" y "fundentes" en los gránulos de clínker presenta las siguientes caracteristicas: en el centro de los gránulos suele apreciarse, a reces, sílice libre, la cual se manifiesta, según Tavasci (6), por la presencia de espacios cuyos contornos constituyen una costra de silicato bicálcico. Es un hecho general que los gránulos de clínker son más compactos exterior que interiormente, debido a una mayor abundancia de celita, es decir, de alúmina y óxido férrico en las zonas más externas. En cuanto a los dos componentes de la celita, el oscuro (aluminato tricálcico) y el claro (aluminoferrito tetracálcico), Tavasci señala para ellos una distribución heterogénea, según se trate de fase vítrea periférica o interior. Incluso los pequeños cristales que denotan un principio de cristalización, y cuya existencia ha podido ser demostrada, escasean más en las zonas corticales de los gránulos, aumentando su frecuencia a medida que la observación se dirige hacia el centro de los mismos (7) y (8).

\section{2--PARTE EXPERIMENTAL.}

A) Preparación de las muestras, técnicas operatorias $y$ método de análisis.

En el segundo de los trabajos antes citados, cuyos resuitados quedan brevemente reseñados en la introducción, se consideraban sólo dos zonas en cada gránulo de clínker, por las razones que en su lugar se exponian (3): la cortical y la interna, siendo arbitraxias en cada caso las magnitudes tanto absolutas como relativas de una y otra. Al confirmarse en todos los casos los resultados experimentales, ello probaba de una manera indirecta que las heterogeneidades en la composición de los gránulos se manlfestaban de manera continua, según las direcciones radiales de los mismos.

En el presente caso, y con objeto de confirmar los hechos de una manera más directa, se ha procedido de modo distinto en cuanto a la separación de las distintas zonas de los gránulos, considerando tres, en lugar de dos.

Se han realizado experiencias con un solo gránulo de clínker, y otras con grupos de dos a seis gránulos, todos ellos análogos en cuanto a tamaño y forma (sensiblemente esférica). Tanto en unas como en otras se sometía a los gránulos a una calcinación previa a $1.000^{\circ} \mathrm{C}$, hasta constancla de peso, tomando nota de éste. A continuación se exponían a un primer tratamiento con ácido clorhídrico, en caliente y con agitación, a fin de que el ataque fuese lo más regular posible y produjese Ia disolnción de sucesivas capas concéntricas.

Una vez se consideraba terminado este primer tratamiento, se separaban los gránulos del medio clorhídrico, se lavaban a fondo con alcohol absoluto, hasta total separación de los productos de ataque sueltos, pero adheridos a la superficie de los gránulos, y se juntaban los líquidos de lavado con la disolución clorhídrica resultante del ataque. En el conjunto se veriflcaba el análisis, con arreglo al método clásılco (9).

El gránulo restante, perfectamente lavado, se sometia a una nueva calcinación a $1.000^{\circ} \mathrm{C}$, hasta peso constante, anotándose este segundo peso. La diferencia entre la primera y segunda pesadas se consideraba como peso de la muestra disuelta.

A contínuación se sometía el gránulo a un segundo tratamlento ácido, con las mismas características del primero. El tercero y último a taque se prolongaba hasta la total disolución del gránulo restante.

En caso de rotura de algún gránulo, la cual podría desvirtuar los resultados al pasar a la disolución partes del mismo, no correspondientes a la zona considerada en el momento, se rechazaba la experiencia. 
Se obtenian asi tres liquidos conteniendo las cantidades disueltas en cada tratamiento sucesivo. Variando el tiempo de cada uno de ellos, a constancia de las demás condiciones de trabajo, se conseguía varlar el espesor de cada capa atacada $y$, por tanto, el tamafio relativo de una a otra de las tres consideradas: la correspondiente al primer ataque, la del segundo y la del tercero.

Se procuró que las cantidades del material disuelto en cada caso fuesen análogas a las que para cada componente a determinar fija el método analítico empleado, diluyendo los liquidos problema en la medida conveniente para conseguir tal fin, cuando era necesario.

Este procedimiento tiene la ventaja, respecto del empleado con anterioridad (3), de que Ias muestras son más representativas de las zonas a las que corresponden, por cuanto que el ataque quimico es bastante uniforme $y$ concéntrico y, variando el tiempo del mismo, se puede regular mejor, como queda dicho, el espesor a que afecta cada uno de los tres tratamientos sucesivos con ácido clorhídrico. En la separación de muestras por medios mecánicos (3), estas condiciones" no podían darse.

En camblo, tiene el inconveniente de no poderse determinar la cal libre ni la pérdida al fuego de cada muestra.

La variación de la cal libre según las distintas zonas del gránulo ya nos es conocida (1), y no tendría otro interés en el caso presente, que el de poder determinar, con mayor precisión y veracidad, tal como ocurria en (3), la composición potencial calculada de cada una de las zonas del gránulo. La variación de la pérdida al fuego es escasa $y$ dice muy poco, como ya se comprobó (3).

\section{B) Resultados.}

Se han estudiado diversos clínkeres de cemento portland coctdos, unos con carbón, otros con fuel-oil y otros con mezclas de carbón y fuel-o1l. De igual manera, unos fueron obtenidos por el proceso de vía húmeda $y$ otros por el de vía seca.

En los cuadros siguientes se dan los resultados del análisis químico, de los. indices y módulos usuales en la química del cemento, de la composición potencial calculada steulendo el método de Bogue (10) y de la fase liquida formada en el proceso de la clinkerización, a las tres temperaturas que indican las fórmulas de Lea y Parker, cuando éstas son aplicables *. Por lo que se refiere al análisis químico, los valores indicados en los cuadros son la media de dos determinaciones concordantes. Se siguió la norma de, en casos de discrepancia, proceder a una tercera determinación $y$ rechazar la experiencia, si ello era aconsejable.

\section{a) Clínker cocido con carbón.}

Los resultados se dan en los cuadros 1 a 4. En el primero se exponen los datos analiticos correspondientes a tres ataques sucesivos de cada uno de seis gránulos análogos, asi como las cifras medias relativas a dichos ataques.

En el segundo constan los módulos hidráulicos, silícico y de fundentes:

$$
\begin{aligned}
\mathrm{MH} & =\frac{\mathrm{CaO}}{\mathrm{SlO}_{2}+\mathrm{Al}_{2} \mathrm{O}_{3}+\mathrm{Fe}_{2} \mathrm{O}_{3}} \\
\mathrm{MS} & =\frac{\mathrm{SiO}_{2}}{\mathrm{Al}_{2} \mathrm{O}_{2}} \frac{\mathrm{Fe}_{3} \mathrm{O}_{3}}{\mathrm{MF}}=\frac{\mathrm{Al}_{2} \mathrm{O}_{2}}{\mathrm{Fe}_{2} \mathrm{O}_{2}}
\end{aligned}
$$

el porcentaje de fase liquida a las tres temperaturas señaladas, según las fórmulas de Lea y Parker (11)**:

$$
\begin{aligned}
& \text { a } 1.340^{\circ} \mathrm{C}: \mathrm{FL}=6,1 \mathrm{Fe}_{2} \mathrm{O}_{3}+\mathrm{MgO} \\
& \text { a } 1.400^{\circ} \mathrm{C}: \mathrm{FL}=2,95 \mathrm{Al}_{2} \mathrm{O}_{3}+2,2 \mathrm{Fe}_{2} \mathrm{O}_{3}+\mathrm{MgO} \\
& \text { a } 1.450^{\circ} \mathrm{C}: \mathrm{FL}=3,0 \mathrm{Al}_{2} \mathrm{O}_{1}+2,25 \mathrm{Fe}_{2} \mathrm{O}_{4}+\mathrm{MgO}
\end{aligned}
$$

y la composición potencial procentual, según las fórmulas de Bogue (10) ***:

$$
\begin{aligned}
& \mathrm{C}_{7} \mathrm{~S}=4,07 \mathrm{CaO}-7,60 \mathrm{SiO},-1,43 \mathrm{Fe}, \mathrm{O}_{2}-6,72 \mathrm{Al}_{2} \mathrm{O}_{2} \\
& \mathrm{C}_{2} \mathrm{~S}=2,87 \mathrm{SiO}_{2}-0,754 \mathrm{C}_{8} \mathrm{~S} \\
& \mathrm{C}_{3} \mathrm{~A}=2,65 \mathrm{Al}_{2} \mathrm{O}_{2}-1,69 \mathrm{Fe}_{2} \mathrm{O}_{2} \\
& \mathrm{C}_{4} \mathrm{AF}=3,04 \mathrm{Fe}_{2} \mathrm{O}_{2}
\end{aligned}
$$

- Slempre que la relación $\mathrm{Al}_{2} \mathrm{O}_{3} / \mathrm{Fe}_{2} \mathrm{O}_{3}$ es supertor a 1,39 . *** Sin terer en cuenta los alcalis. 
Todos los cálculos corresponden a los datos del cuadro primero.

En el cuadro tercero constan Ios datos anaIíticos de los tres ataques sucesivos de seis muestras constituídas respectivamente por un número de gránulos varlable de uno a sels, así como Ias cifras medias correspondtentes.

El cuadro cuarto, equivalente al segundo, corresponde a los mismos cálculos efectuados con los datos del tercero.

\section{b) Clínker cocido con carbón y fuel-oill.}

Los resultados analíticos figuran en el cuadro quinto $y$ se refieren a los tres ataques de las muestras constituidas por uno y seis grénulos, respectivamente, así como a los valores medios.

En el cuadro sexto se dan los resultados calculados con los datos analíticos anteriores.

\section{c) Clínker coeido con fuel-oll.}

Ios datos analíticos constan en los cuadros 7 y 9, análogos a los cuadros 1 y 3 ; los datos calculados se dan en los 8 y 10 , equivalentes a $\operatorname{los} 2$ y 4 .

Los cuadros 11 y 12 , equivalentes a $\operatorname{los} 5$ y 6 , se refieren a otro clínker de distinta procedencia.

Debe advertirse que en los cuadros 8 y 10 faltan por consignar algunos datos relativos a fase líquida, a causa de que, al ser la relación $\mathrm{A} / \mathrm{F}^{\mathbf{2}}\left(\mathrm{Al}_{2} \mathrm{O}_{3} / \mathrm{Fe}_{3} \mathrm{O}_{3}\right)$ inferior a 1,38 en los correspondientes casos, no son aplicables a los mismos las fórmulas de Lea y Parker.

De Igual manera, los espacios sin cubrir, relativos a la composición potencial, en los cuadros 2 y 4, se deben a que, utllizando ias fórmulas de Bogue, resultan valores negativos para el $\mathbf{C}_{\boldsymbol{y}} \mathbf{S}$, lo que indica que aquéllas no son aplicables.

De la consideración de los resultados que quedan expuestos se desprende una serie de hechos que se ponen de maniflesto en lo que sigue. Como puede comprobarse, son independientes del tipo de combustible o mezcla de combustibles empleados en la cocción del clínker, asi como de la modalidad del proceso utilizado en su fabricación (vía seca o via húmeda). Estos hechos se aprecian, tanto en la mayoría de los valores aislados hallados para uno o varios gránulos, como en las cifras medias.

En primer lugar se observa un aumento de sílice a medida que el ataque químico profundiza hacia el interior de los gránulos.

En segundo lugar queda de maniflesto una disminución de óxido férrico y de alúmina, conforme el ataque quimfco avanza en la dirección señalada. Consecuencia de ello es que la suma de sesquíoxidos $\mathrm{R}_{2} \mathrm{O}_{3}$ sigue la misma ley de variación.

También la magnesia parece tender a disminutr cuando la zona considerada se adentra hacia el centro del gránulo.

Por el contrario, el SO, parece tender a aumentar hacia dicho centro.

Respecto de la cal total, nada puede decirse, si bien parece que no se observan apenas variaciones dignas de consideración.

Las diferencias que se aprecian entre los valores de las columnas que se refleren a los primeros ataques, y lo mismo por to que respecta a los segundos y terceros, para distintos gránulos o grupos de gránulos, se deben a que, en cada caso, son diferentes los espesores de las zonas atacadas en primero, segundio y tercer lugar, respectivamente, como consecuencia de la distinta duración de dichos ataques.

Pero las diferencias halladas entre el primer ataque y el segundo, y entre éste y el tercero, son, en general, siempre del mismo signo para cada componente analtzado, constituyendo esto una prueba de Ia variación continua del porcentaje de dichos componentes, a lo largo de las direcclones radiales de los gránulos. 


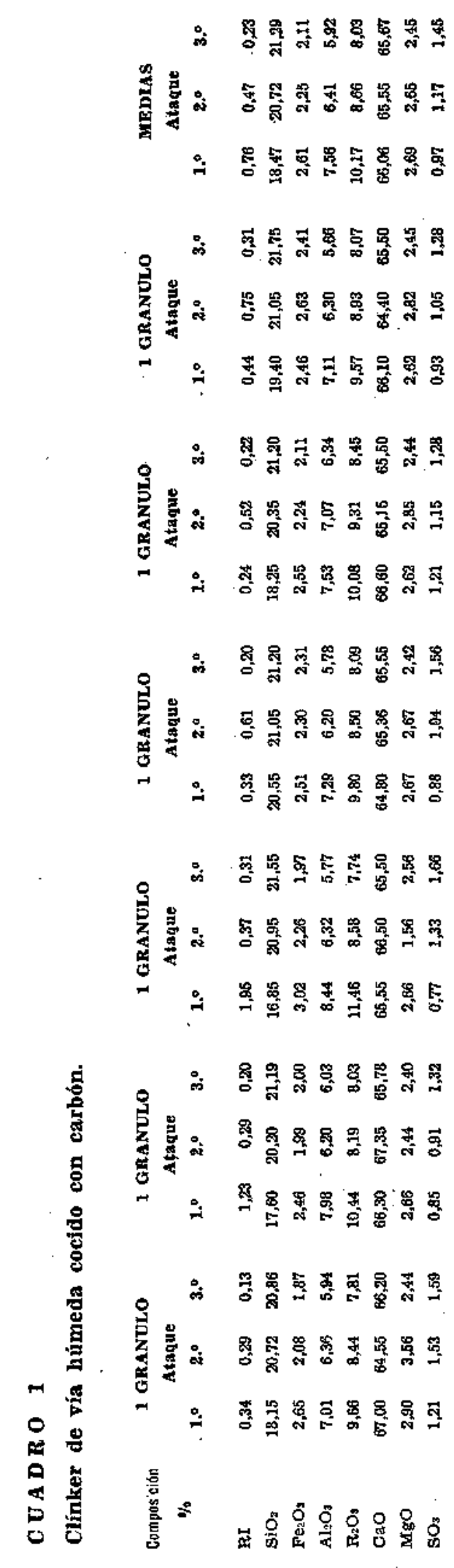

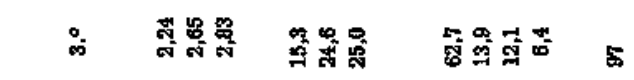

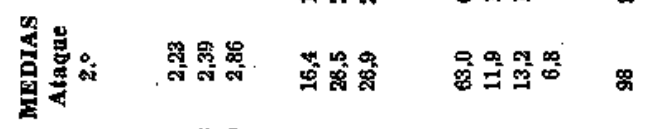

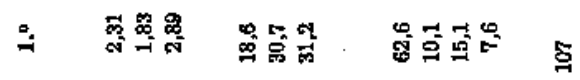

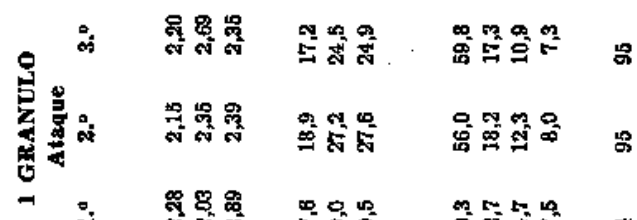

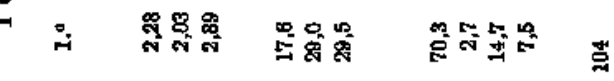

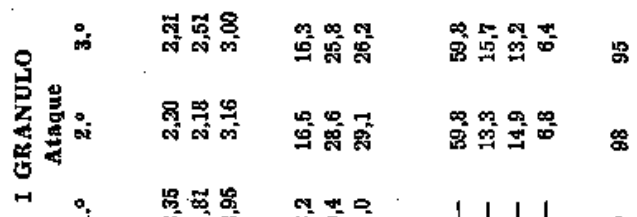

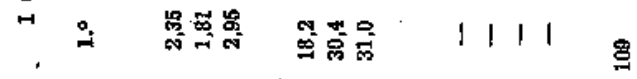

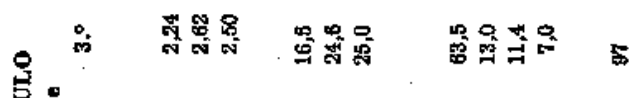

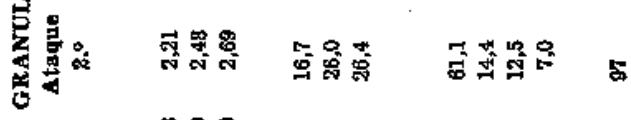

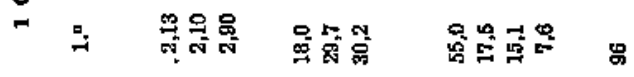

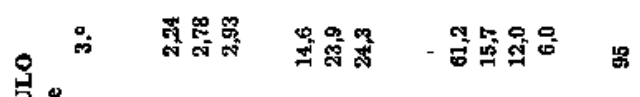

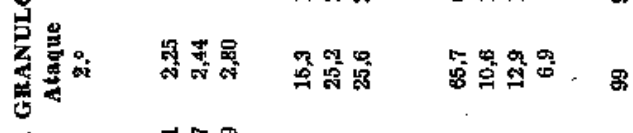

-

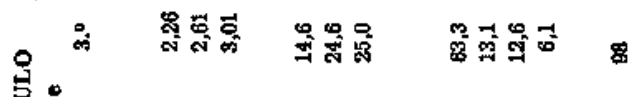

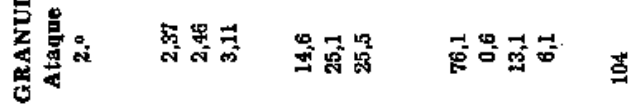

- ․․ำ

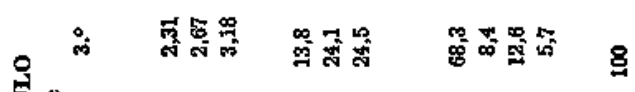

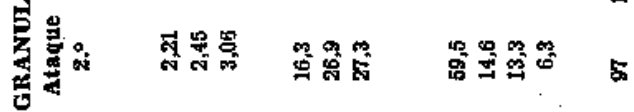

-

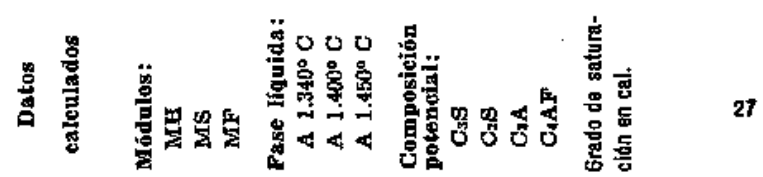




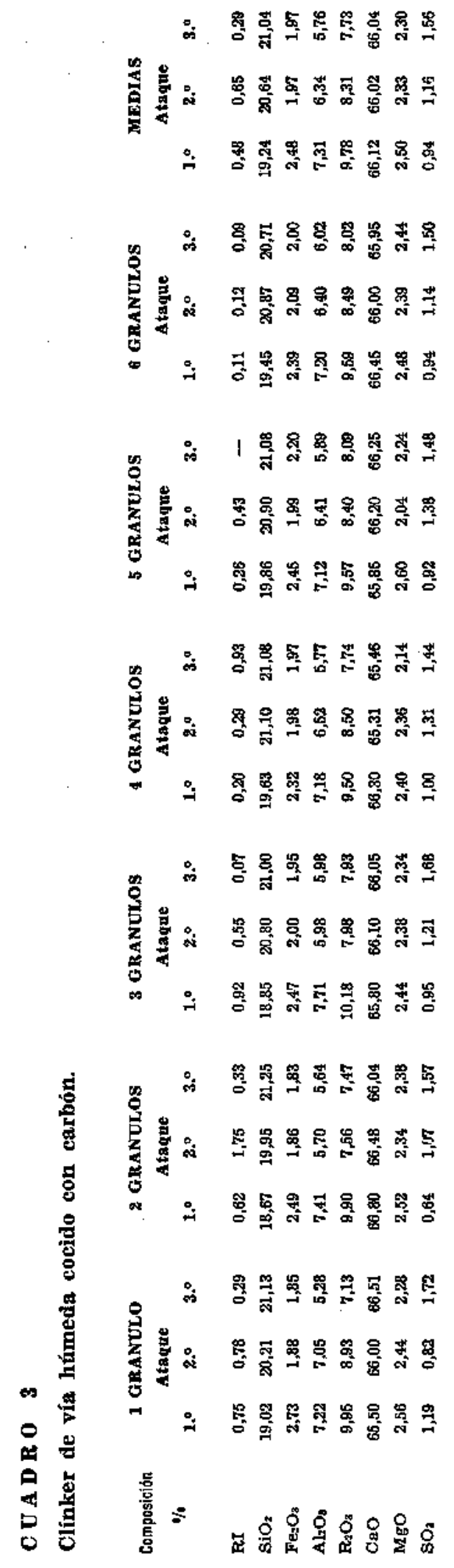

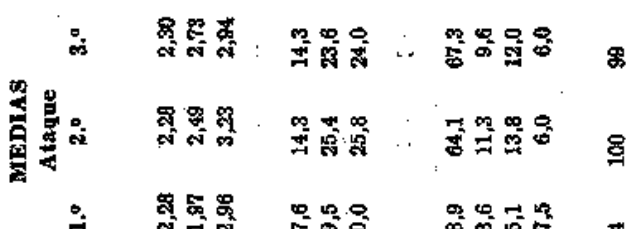

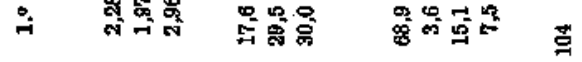

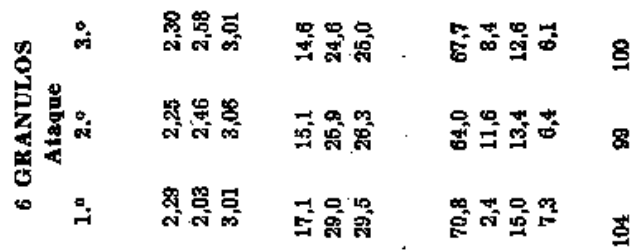

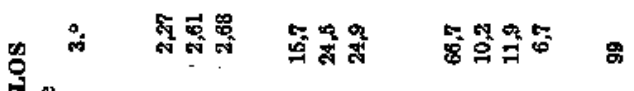

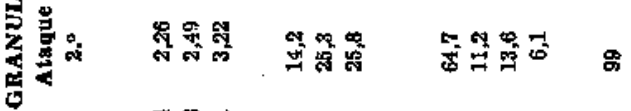

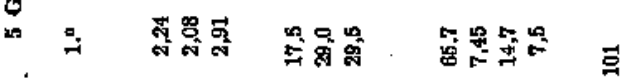

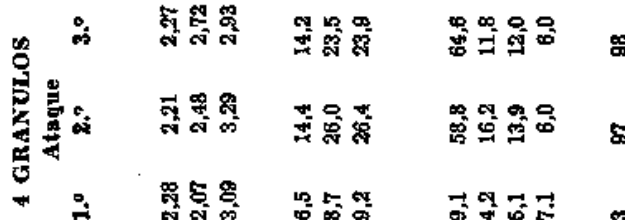

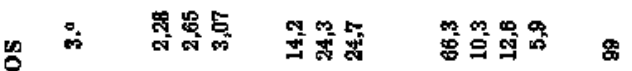

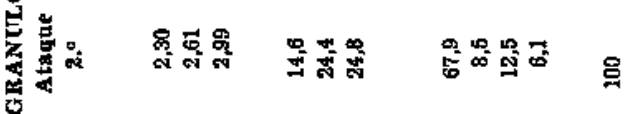

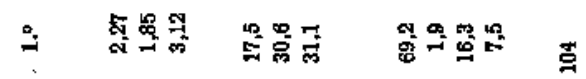

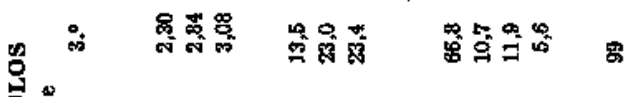

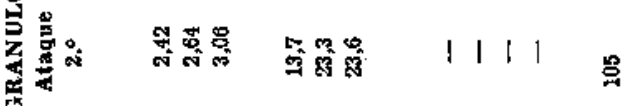

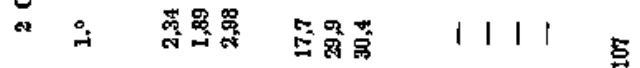

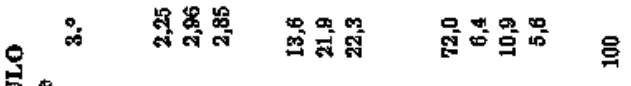

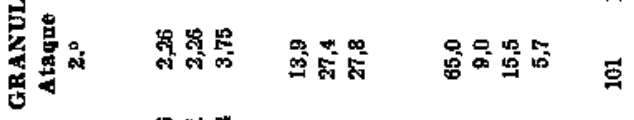

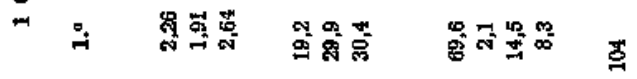

$\circ$

总

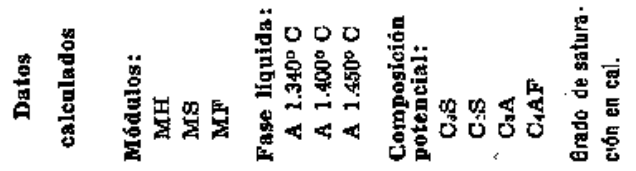


Cundro

Clínker de vía húmeda cocido con carbón y fuel-oil.

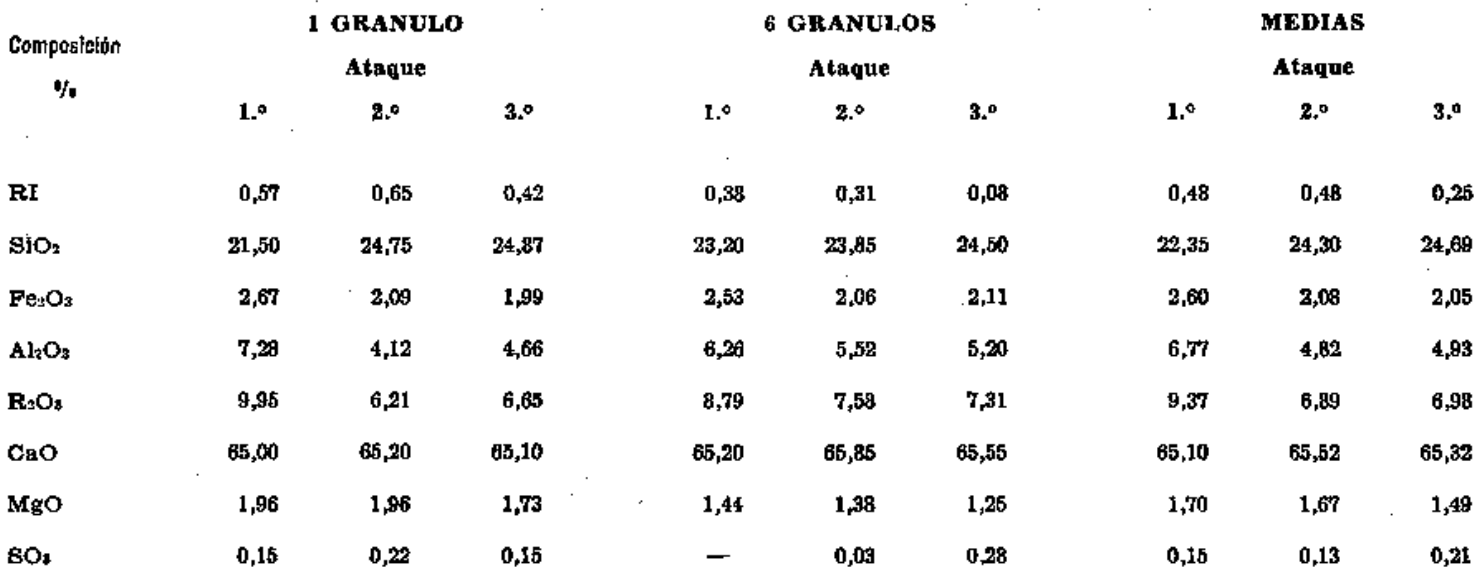

CUADRO 6

Clínker de vía húmeda cocido con carbón y fuel-oil.

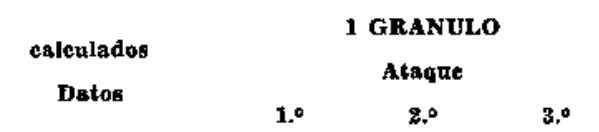

MH

MS

MF

$\begin{array}{lll}2,07 & 2,11 & 2,07 \\ 2,16 & 3,99 & 3,74 \\ 2,73 & 3,97 & 2,34\end{array}$

Fase líquida:

$A+3400^{\circ} \mathrm{O}$

A $1.400^{\circ} \mathrm{C}$

A $1.460^{\circ} \mathrm{O}$

$14,7 \quad 13,9$

29,3

18,7

19,9

28,8

$19,0 \quad 20,2$

Composición

potencial:

$\mathrm{C}_{2} \mathrm{~S}$

$\mathrm{C}_{8 \mathrm{~A}}$

CAAF

Grado do saluración

an cal.

$\begin{array}{rrrrrr}48,4 & 46,6 & 41,8 & 43,4 & 46,7 & 42,6 \\ 25,2 & 35,9 & 39,9 & 33,9 & 33,2 & 38,2 \\ 14,8 & 7,4 & 9,0 & 12,3 & 11,1 & 10,2 \\ 8,1 & 6,4 & 6,1 & 7,7 & 6,3 & 6,4\end{array}$

93

89

8

B6
6 GRANULOS

Ataque

2.a

3.0

$$
2,04
$$$$
2,64
$$

2,47

$\begin{array}{ll}2,09 & 3,06 \\ 3,15 & 3,35 \\ 2,68 & 2,46\end{array}$

$25,5 \quad 22,2$

$25,9 \quad 22,6$

14,1

21, 2

21,6
MEDIAS

Ataque

1. $2 .^{\circ}$

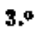

$\begin{array}{lll}2,05 & 2,10 & 2,06 \\ 2,40 & 3,57 & 3,54 \\ 2,60 & 2,32 & 2,40\end{array}$

$17,6 \quad 14,3 \quad 14,0$

$27,4 \quad 20,5 \quad 20,5$

$\begin{array}{lll}27,9 & 20,8 & 20,9\end{array}$ 


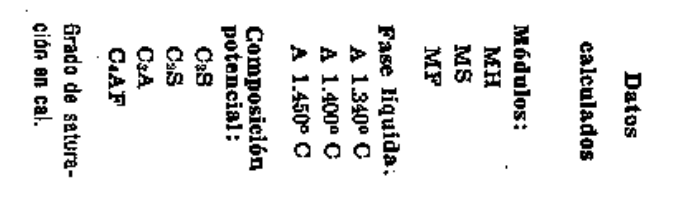

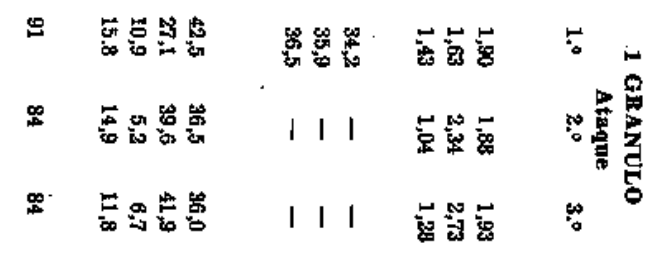

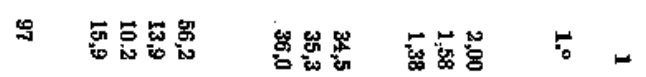

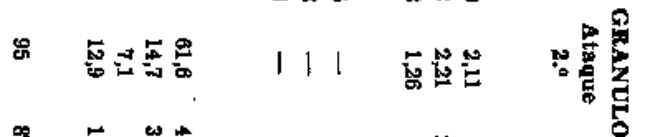

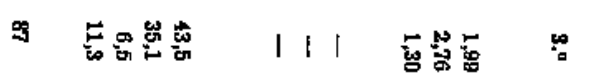

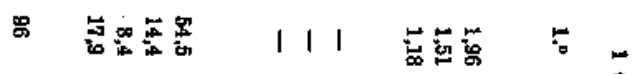

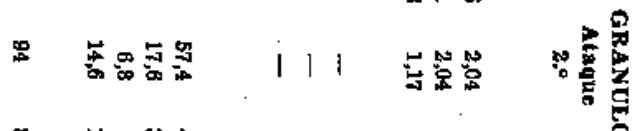

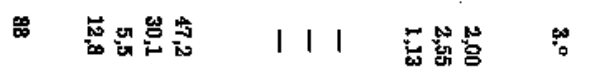

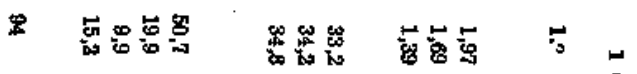

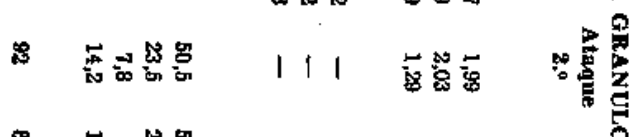

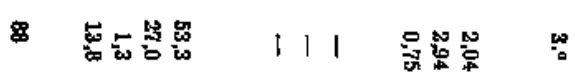

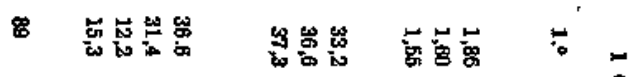

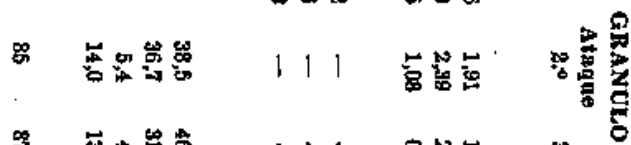

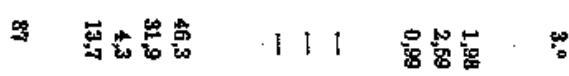

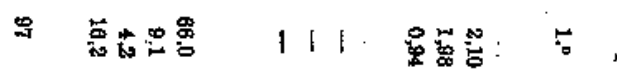

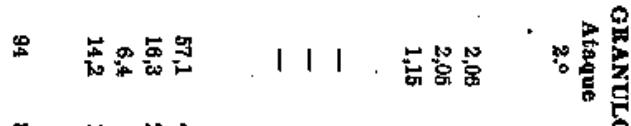

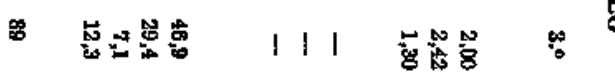

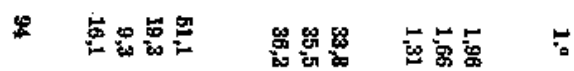

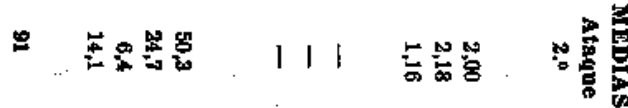

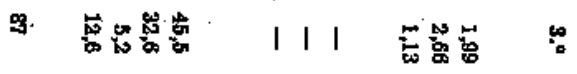

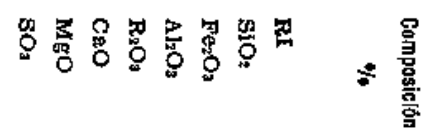

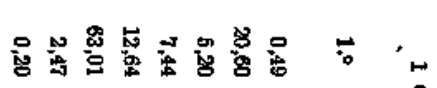

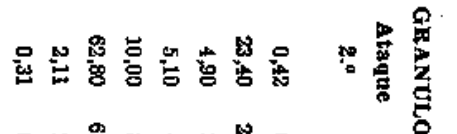

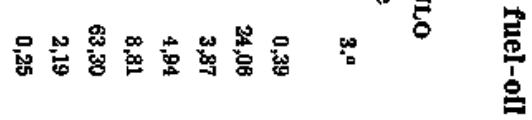

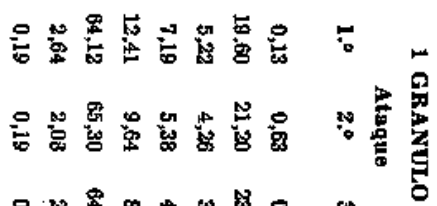

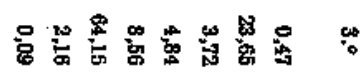

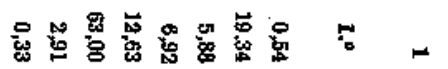

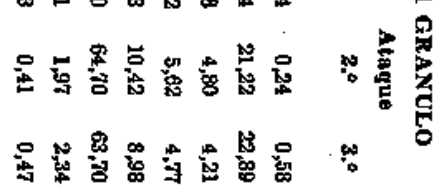

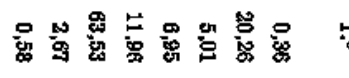

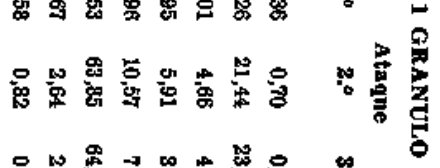

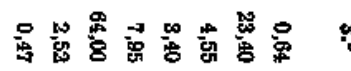

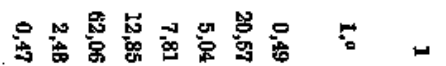

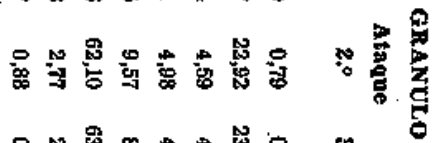

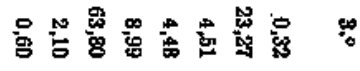

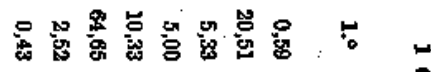

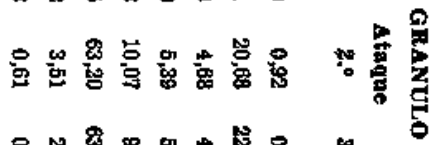

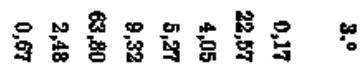

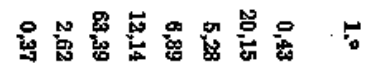

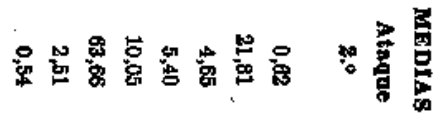

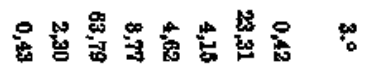




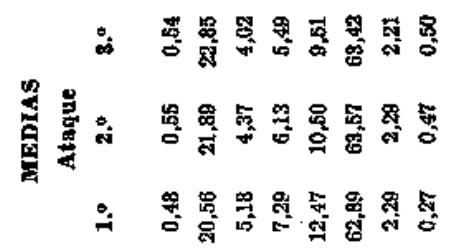

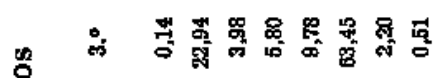

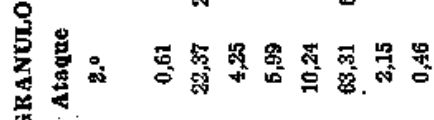

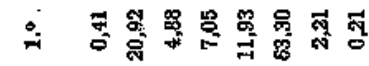

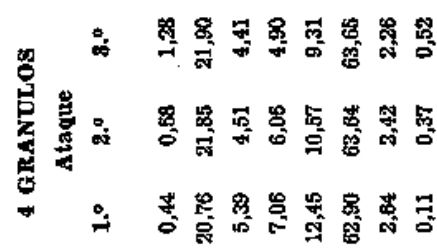

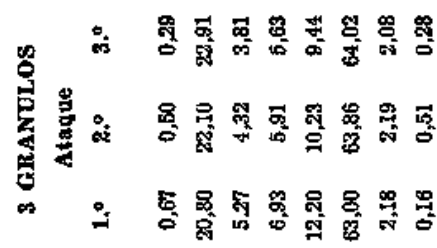
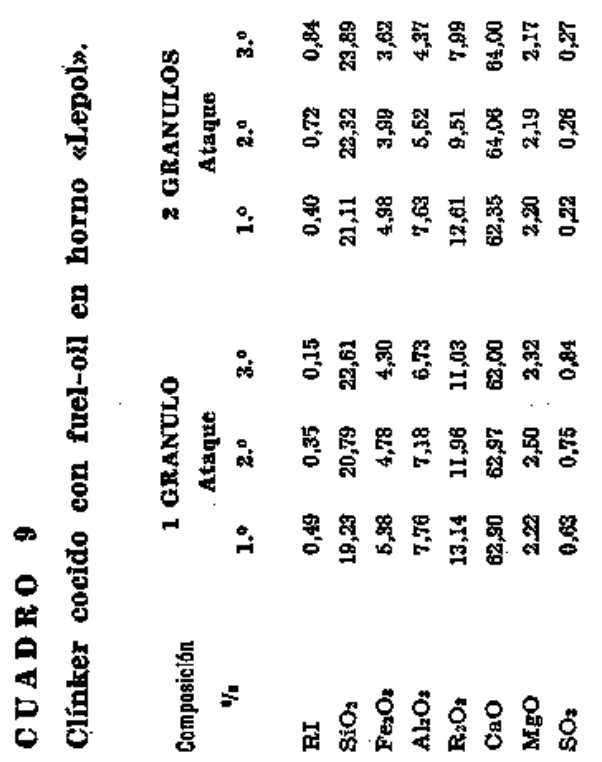

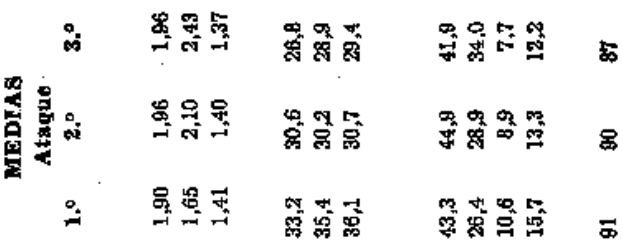

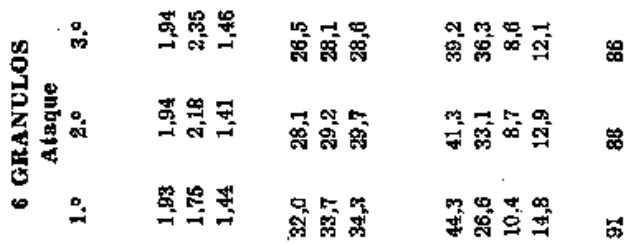

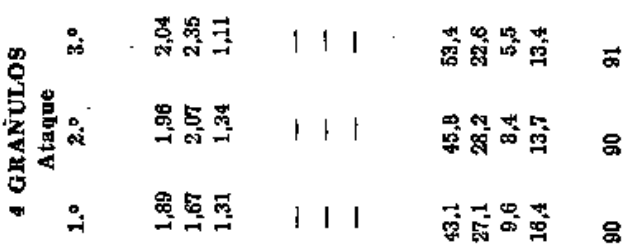

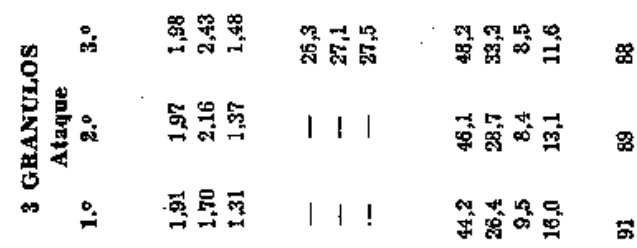

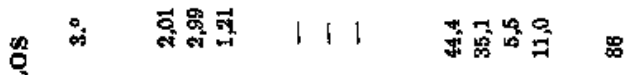

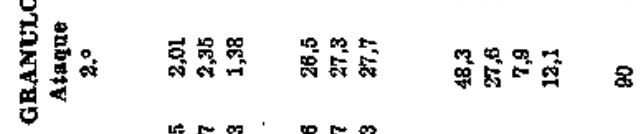

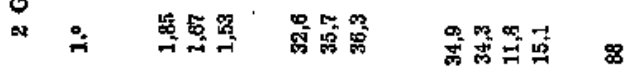

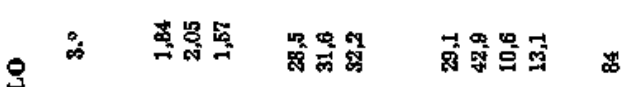

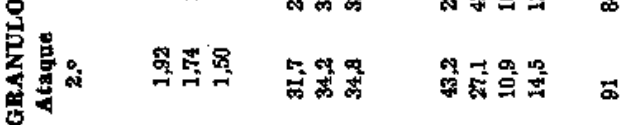

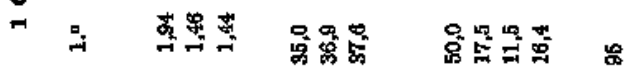

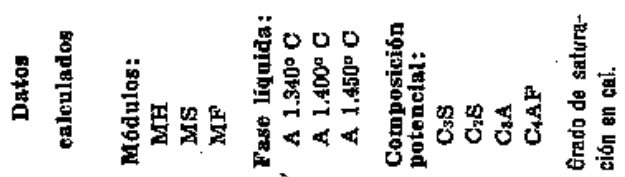


CUADRO 11

Clínker de vía húmeda cocido con fuel-oll.

\begin{tabular}{|c|c|c|c|c|c|c|}
\hline \multirow{2}{*}{$\begin{array}{c}\text { Composición } \\
\%\end{array}$} & \multicolumn{3}{|c|}{ Ataque } & \multicolumn{3}{|c|}{ Ataque } \\
\hline & $10^{\circ}$ & $20^{\circ}$ & $3.0^{\circ}$ & $10^{\circ}$ & 2.0 & $80^{\circ}$ \\
\hline RI & 0,42 & 0,38 & 0,36 & 0,19 & 0,25 & 0,28 \\
\hline SiO: & 22,05 & 23,50 & 25,10 & 22,45 & 24,20 & 24,10 \\
\hline $\mathrm{Fe}_{2} \mathrm{O}_{2}$ & 2,91 & 2,44 & 2,40 & 3,03 & 2,84 & 2,70 \\
\hline $\mathrm{Al}_{2} \mathrm{O}_{3}$ & 6,50 & 5,41 & 5,27 & 6,38 & 5,28 & 5,80 \\
\hline $\mathrm{R}_{2} \mathrm{O}_{\mathbf{z}}$ & 9,41 & 7,85 & 7,67 & 9,41 & 8,12 & 8,60 \\
\hline $\mathrm{CaO}$ & 64,50 & 64,60 & 63,30 & 64,50 & 68,85 & 63,50 \\
\hline MgO & 2,38 & 2,33 & 2,25 & 2,32 & 2,32 & 2,16 \\
\hline SO, & 0,35 & 0,28 & 0,31 & 0,30 & 0,31 & 0,37 \\
\hline
\end{tabular}

CUADRO 12

Clínker de vía húmeda cocido con fuel-oll.

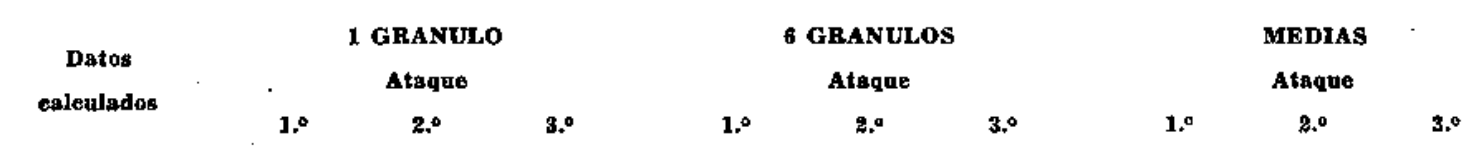

Môdulos:

$\begin{array}{llllllllll}\text { MH } & 2,05 & 2,06 & 1,93 & 2,02 & 1,98 & 1,94 & 2,03 & 2,02 & 1,98 \\ \text { MS } & 2,34 & 2,89 & 3,27 & 2,38 & 2,08 & 2,80 & 2,36 & 2,98 & 3,03 \\ \text { MF } & 2,23 & 2,22 & 2,19 & 2,10 & 1,86 & 2,18 & 2,16 & 2,04 & 2,18\end{array}$

Fase liquilda:

$\begin{array}{llllllllll}\text { A } 1.340^{\circ} \mathrm{C} & 20,1 & 17,2 & 16,9 & 20,8 & 19,6 & 18,6 & 20,5 & 18,4 & 17,8 \\ \text { A } 1.400^{\circ} \mathrm{C} & 28,0 & 23,7 & 23, \mathrm{I} & 27,8 & 24,1 & 25,5 & 27,9 & 23,9 & 24,3 \\ \text { A } 1.450^{\circ} \mathrm{C} & 28,4 & 24,1 & 23,5 & 28,3 & 24,6 & 25,0 & 28,4 & 24,3 & 24,7\end{array}$

Composición poteneial:

\begin{tabular}{|c|c|c|c|c|c|c|c|c|c|}
\hline $\mathrm{C}_{8} \mathrm{~S}$ & 47,1 & 44,5 & 28,0 & 44,7 & 36,4 & 31,8 & 45,9 & 40,4 & 29,9 \\
\hline $\mathrm{C}_{2} \mathrm{~S}$ & 27,6 & 93,9 & 50,8 & 30.7 & 42,0 & 45,2 & 29,3 & 38,0 & 48,1 \\
\hline $\mathrm{C}_{3} \mathrm{~A}$ & 12,3 & 10,2 & 9,9 & 11,8 & 9,2 & 11,1 & 12,1 & 9,7 & 10,5 \\
\hline $\mathbf{C}_{4} \mathbf{A F}$ & $B, 8$ & 7,4 & 7,3 & 9,2 & 8,6 & 8,2 & 9,0 & 8,0 & 7,8 \\
\hline
\end{tabular}

firado de saturat [ón en cal.

$91 \quad 88 \quad 91$

$\begin{array}{lll}90 & 85 & 84\end{array}$

$90: \quad 86 \quad 83$ 
Las citadas variaciones en la sílice, alúmina, óxido férrico y magnesta dan lugar, a su vez, a las de los módulos calculados, a la de los porcentajes de fase líquida determinados por las fórmulas de Lea y Parker, cuando son apllcables, y a las de las composictones potenciales halladas por el cálculo de Bogue.

Estas variaciones son las previsibles. Asi, por ejemplo, el módulo hidráulico apenas varía en las distintas zonas, puesto que no variando apenas la cal $y$ variando en sentidos contrarios la sillice, por una parte, y la alúmína y el óxido, por otra, puede haber, como de hecho parece que hay, una compensación.

Por el contrario, el módulo silícico crece hacia el interior de los gránulos, al aumentar la sílice y disminulr la alúmina y el óxido férrico.

En cuanto al módulo de fundentes, parece tener tendencia a disminuir hacia las partes internas de Ios gránulos, lo que denota una pequeña desproporción entre la alúmina y el óxido férrico, tanto más favorable a la: primera cuanto más externas son las zonas consideradas.

Las diferencias entre las cifras de alúmina, óxido férrico y magnesia hacen tambièn que las cantidades de fase liquida a las temperaturas a que corresponden las fórmulas de Lea y Parker sean decrecientes hacia el interior de los gránulos.

Por lo que respecta a la composición potencial calculada, los silicatos tricálcico y bicálcico varían en sentidos contrarios: el primero parece crecer algo hacia las partes exteriores de los gránulos, mientras el segundo aumenta hacia el interlor. El aluminato tricálcico y el aluminoferrito tetracáleico son ambos más abundantes en las partes externas.

Todos estos hechos quedan grăficamente de manifiesto en el esquema de la figura, en la que las flechas indican sentidos crecientes.

Entre si guardan una estrecha relación y pueden explicar muchas de las acciones observadas en el proceso industrial de la cocción. Así, por ejemplo, la acción fundente y mineralizadora de Ia alúmina, el óxìio férrico y Ia magnesia y su contribución a la formación

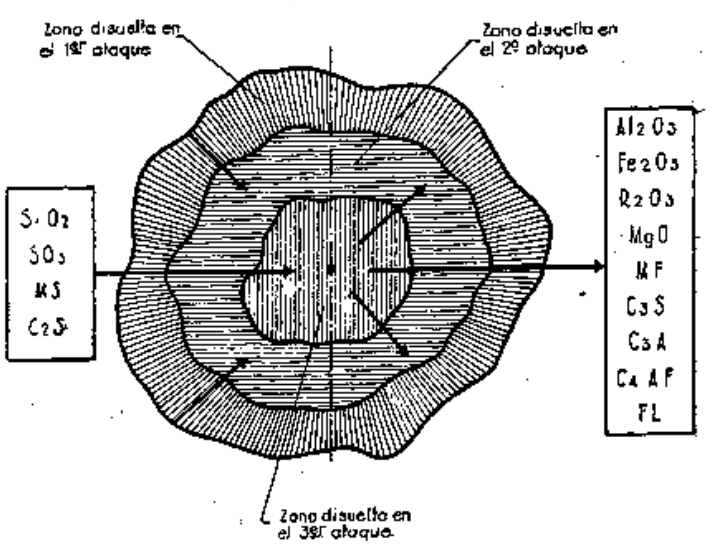

de fase líquida, vehiculo en el cual deben transcurrir con mayor rapidez y facilidad las reacciones entre la silice y la cal, puede hacer que en las zonas en que aquellos componentes abundan más, o se concentran, se formen de preferencia los stlicatos cálcicos de mayor basicidad.

Esto pondría en claro el hecho de la tendencia a ser más abundante el $\mathrm{C} S$ en las zonas periféricas de los gránulos, donde, además, la temperatura debe ser mayor. Por igual razón la cal libre ha de ser, como lo es, más escasa en dichas zonas.

Respecto del primer punto hay que hacer notar que, como ya quedó indicado, abundan los clínkeres cuyos gránulos presentan una mayor riqueza de silfcato bicálcico en las zonas corticales, particularmente si han incorporado gran cantidad de ceniza del combustible. Estos resultados se refleren a observaciones microscóplcas, en tanto que los anterlores se basan en un cálculo tébrico. No son, por consiguiente, perfectamente comparables.

La última palabra en cuanto a la mayor - menor abundancia de $\mathbf{C}_{3} \mathbf{S}$ en la periferia, en relación con las zonas nucleares, como hecho general, podrá decirla una observación microscóptca estadística de diversos clínkeres cocidos con carbón, fuel y mezolas, tanto por vía húmeda como por vía seca. $\mathrm{El}$ análisis químico y el cálculo de Bogue se manifiestan a este respecto insuflcientes.

De los hechos anteriores parece deductrse, en principlo, que la heterogeneidad entre las 
zonas periférica $\mathrm{y}$ las intermedias, asi como entre éstas y las interiores, ha de ser tanto menor cuanto más pequeños sean los gránulos.

La confirmación definitiva de este punto habrá de darla el estudio comparativo de varias geries de gránulos de la misma procedencia y tamaños graduales.

Para este estudto es aplicable la técnica utilizada en este trabajo, mejor que la empleada con anterioridad (3), pues la separación por medios mecánicos de las tres zonas en los gránulos pequeños es muy difícil o imposible.

También en este aspecta la observación mlcroscópica puede ser un buen complemento.

\section{D) Conclusiones.}

1. a Se conflrman los resultados obtenidos en un trabajo anterior (3), en cuanto a la heterogeneidad de los gránulos de clínker de cemento portland, en el sentido de ser más elevados en las zonas periféricas de los mismos los contenidos en alúmina, óxido férrico, magnesia, silicato tricálctco, aluminato tricálcico y aluminoferrito tetracálcico, asi como los valores correspondientes al módulo de fundentes y al contenido en fase liquida. For el contrario, escasean nás en dichas zonas la silice, el anhidrido sulfúrico, la cal libre y el stlicato bicálcico, siendo menor el valor correspondiente al módulo silícico.

2. ${ }^{a}$ Las variaciones en los valores indicados se manifiestan como continuas a lo largo de las direcciones radiales de los gránulos de clínker.

3. Estos resultados son independientes de la naturaleza de los combustíbles empleados en la cocción del clínker, así como del tipo de proceso seguido para la misma.

4. a Parece, en principio, que las heterogeneidades deberán ser tanto menores cuanto menor sea el tamaño de los gránulos, y, en tal sentído, la técnica utilizada en el presente trabajo permitirá conftrmar experimentalmente estos extremos, aplicándola a series de gránulos de igual procedencia $y$ tamaños graduales.

5. Como complemento de lo anterior, así como para diluctdar to relativo a la distribución de los sillicatos tricálcico y bicálcico en las distintas zonas de los gránulos de clínker, la observación microscópica realizada sobrè gran número de muestras de la más diversa condición puede ser de gran utilidad.

\section{B I B LIO GRA F I A}

(1) CalleJa, J.: An. Fis. y Quím. B 48, 531 (1952); Zement-Kalk-Gips 5/41, 206 (1952).

(2) A. S. T. M. STANDARDS: C 114-47, 57 (1949).

(3) Cartevta, J.: I. T. C. C. Monografia 146. "Rev. Ciencia Aplicada", núms. 45, b6 y 47 (1955).

(4) LeoptTallier, P., y JaMes, J. M.: Revue des Materiaux, número especial, octubre 1950 ("Publications Téchniques", 28 à 33 ).

(5) Cement \& Lime Manufacture, XXIV, 2, 32 (1951).

(6) Tavasci, B.: Curso de. Especialización en Cemento. I. T. c. C. Madrid, octubre 1950.

(7) INsLEY, H.: Jorun. Res. Nat. Bureau Standards 25, 2, 295 (1940).

(8) A. S. T. M. STANDaRds: C 114-47, 38 (1949); NELC 3.01.

(10) Boguz, R. H.: The Chemistry of Portland Cement, 2. ${ }^{\mathrm{a}}$ ed. 754, N. Y. (1955).

(11) LEA, F. M., y PakKeR, T. W.: Butlaing Research, Tech. Paper 16 (1935). 